\title{
DESAIN MEJA ADMINISTRASI SWAJASA 57
}

\author{
Etwin Fibrianie $^{1}$ \\ ${ }^{1}$ Staf Pengajar Program Studi Desain Produk, Jurusan Desain \\ Politeknik Negeri Samarinda \\ Randu Chan Limin ${ }^{2}$ \\ ${ }^{2}$ Mahasiswa Program Studi Desain Produk, Jurusan Desain \\ Politeknik Negeri Samarinda
}

\begin{abstract}
Abstrak
Admin Jasa merupakan memiliki kegiatan catat-mencatat, surat-menyurat, pembukuan ringan, ketik-mengetik, agenda dan sebagainya yang bersifat teknis ketatausahaan dalam bidang jasa. Untuk menunjang pelaksanaan kegiatan di bagian Admin Jasa diperlukan sarana kerja yang baik dan sesuai dengan kebutuhan di dalamnya. Salah satu sarana kerja yang mempengaruhi dalam kegiatan dibagian admin jasa ini adalah meja kerja. Seiring dengan perkembangan jasa yang dibutuhkan terutama di bidang admin, yang menuntut adanya informasi yang berkualitas untuk mendukung kelancaran proses pelayanan terhadap pelanggan. Harapan tersebut dapat dipenuhi dengan adanya pelayanan yang baik, cepat dan dapat memuaskan pelanggan. Permasalahan tersebut meliputi penempatan printer yang kurang tepat dan kurangnya space khusus tiga printer admin yang terdiri dari printer biasa, printer bill PPOB (Payment Point Online Bank), printer stempel. Penempatan papan ketik/keyboard dan CPU (Central Processing Unit) yang kurang tepat pada meja tersebut. Dan yang dibutuhkan seorang admin adalah laci kasir. Transaksi dengan konsumen/pelanggan dilakukan dalam satu meja biasa yang membuat kinerja operator tidak maksimal dalam proses pelayanan terhadap konsumen. Sehingga diperlukannya penyesuaian mesin, alat dan perlengkapan kerja terhadap tenaga kerja yang dapat mendukung kemudahan, kenyamanan dan efisiensi kerja. Metode yang digunakan adalah Preliminary Design, Design Development, Final Design \& Prototyping.
\end{abstract}

Kata kunci: admin jasa, desain, meja kerja. 
Vol. 2, No. 2, April 2015

\begin{abstract}
Admin Services is an activity that includes notes, correspondence, light bookkeeping, typing, agendas etc that is technical the effort in the field of services. To support the implementation of activities in the Admin services needed of the means a good work and in accordance with the needs of in it. One of the means work that affects the activities in the admin services of this is a work desk. Along with the development of services that are needed, especially in the field of admin, that demands of the information that qualified to support the smooth process of customer service. The hope that can be filled with a good services, fast and can be contented customers. The problem covering placement of the printer that lack of right and the lack of the special space admin three consisting of the printer usual, printer bill PPOB (payment point online bank), printer stamp. Placement of the keyboard and the CPU (central processing unit) that less right at the table. And desperately needed an admin is teller drawer. Transactions with customers carried out in one of the usual table that made the operator performance not up in the process of service to consumer. So the need for adjustment machine, tools and work equipment to the workforce that can support the ease, comfort, and work efficiency. The method used is the preliminary design, design development, final design \& prototyping
\end{abstract}

Keywords: admin services, design, work desk.

\section{Pendahuluan}

Swajasa 57 merupakan sebuah usaha yang bergerak di bidang jasa yang melayani berbagai permintaan pelanggan, seperti menerima transfer dan kirim uang ke semua bank, travel \& carter mobil, pembuatan spanduk, kartu nama, stempel, cetak foto, pembayaran asuransi, print data dan fax, pengiriman paket PT. Pos dan JNE. Dalam menjalankan aktivitasnya, Swajasa57 menggunakan meja tenaga administrasi. Namun meja tersebut hanya meja biasa dan kurang membantu dalam proses pekerjaan yang dilakukan oleh tenaga administrasi. Terdapat beberapa bagian yang kurang sesuai, seperti tempat printer, CPU komputer, serta kasir pada meja admin jasa tersebut. Ruangan yang kecil berukuran 1,4 x 2 x 1,8 $\mathrm{M}$ membuat meja tersebut tidak sesuai dengan alat dan proses pekerjaan admintrasi Swajasa57.

Didapati beberapa permasalahan dengan meja admin Swajasa57. Permasalahan tersebut meliputi penempatan printer yang kurang tepat, belum adanya space khusus untuk tiga macam printer yang terdiri dari printer biasa, printer bill PPOB (Printer bukti pembayaran), printer stempel. Penempatan keyboard dan CPU kurang tepat. Dan laci kasir yang belum tersedia pada meja tersebut.

Dari survey yang sudah dilakukan yaitu proses pekerjaan admin swajasa57 seperti tulis menulis, mengetik, mengoperasikan komputer, print bukti pembayaran dan transaksi dengan konsumen/pelanggan dilakukan dalam satu meja yang biasa atau meja transaksi biasa 
Etwin Fibrianie, Randu Chan Limin, Desain Meja Administrasi Swajasa 57

yang membuat kinerja operator tidak maksimal dalam proses pelayanan terhadap konsumen. Sehingga diperlukannya sebuah desain meja kerja admin swajasa57 dengan penyesuaian mesin, alat dan perlengkapan kerja terhadap tenaga kerja yang dapat mendukung kemudahan, kenyamanan dan efisiensi kerja.

\section{Metode Penelitian}

Dalam mendesain produk ini dilaksanakan dalam babarapa tahapan desain yang dilaksanakan secara terus menerus. Tahapan desain tersebut adalah:

1. PRELIMINARY DESIGN. Yaitu Pengumpulan data dan informasi, analisis data berdasarkan konsep desain makro yang meliputi analisis (konsep fungsi, konsep pemakai, konsep pasar, dan konsep produk), penyusunan program desain dan sketsa awal. Preliminary desain terdiri atas perumusan masalah, tinjauna pustaka, analisis dan spesifikas desain,

2. DESIGN DEVELOPMENT. Pada tahap ini dibuat alternatif gambar komponen serta rancangan secara wire diagram dengan bentuk 3D (tiga dimensi). Dari bagan yang tertera di atas terdiri dari: desain alternatif, pengembangan alternatif desain.

\section{FINAL DESIGN \& PROTOTYPING.}

Dibuat gambar-gambar kerja yaitu gambar presentasi 3D dan gambar teknik (gambar tampak, gambar potongan, gambar detail dan spesifikasi teknis produk). Tahapan selanjutnya adalah pembuatan komponen-komponen dilakukan assembling (exploded) atau perakitan sehingga menjadi produk (prototype).

\section{Pembahasan}

Langkah awal mendesain dengan melakukan analisis aktivitas dan kebutuhan untuk mengetahui apa saja aktivitas yang berhubungan dengan produk yang akan dibuat. Setelah diketahui aktivitasnya, maka akan diketahui kebutuhan komponen yang harus ada pada produk. Adapun aktivitas yang dilakukan oleh admin swajasa57 ditunjukkan dalam tabel 1, yaitu:

Dari analisis aktivitas dan kebutuhan yang terdapat pada tabel 1, maka didapatkan kebutuhan komponen yang diperlukan dalam produk, yaitu: (1) Rak peletakkan 3 macam printer yang berbeda, (2) Laci untuk menyimpan alat tulis kantor dan laci untuk uang, (3) Space datar khusus untuk menulis, meletakkan komputer dan CPU.

Analisa ergonomi dilakukan untuk meminimalkan resiko kesehatan dan keselamatan dalam produk yang dirancang. Dengan begitu efisiensi, kesehatan, keselamatan, dan kenyamanan dalam melakukan kegiatan menggunakan produk dapat maksimal. Sedangkan analisa antropometri dilakukan guna mendapatkan dimensi atau ukuran produk yang sesuai dengan tubuh pengguna. Aktifitas-aktifitas yang telah dianalisis membutuhkan fasilitas yang ergonomis agar kenyamanan pengguna ketika menggunakan produk ini terjamin. 
Tabel 1. Analisis Aktivitas dan Kebutuhan

\begin{tabular}{|l|l|l|l|}
\hline No. & \multicolumn{1}{|c|}{ Aktivitas } & \multicolumn{1}{|c|}{ Kebutuhan } & \multicolumn{1}{|c|}{ Fasilitas } \\
\hline 1. & Mencetak dokumen/file & $\begin{array}{l}\text { Area datar untuk meletakkan } \\
\text { 3 alat cetak/printer }\end{array}$ & $\begin{array}{l}\text { Meja kerja yang } \\
\text { menyediakan tempat } \\
\text { khusus untuk tiga jenis } \\
\text { printer yang berbeda. }\end{array}$ \\
\hline 2. & Menulis & $\begin{array}{l}\text { Area datar untuk melakukan } \\
\text { kegiatan menulis }\end{array}$ & $\begin{array}{l}\text { Memiliki ruang atau } \\
\text { area datar yang cukup } \\
\text { luas untuk kegiatan } \\
\text { bekerja seperti menulis, } \\
\text { mengetik menggunakan } \\
\text { papan keyboard, dan } \\
\text { untuk meletakkan } \\
\text { komputer dan CPU }\end{array}$ \\
\hline 3. & $\begin{array}{l}\text { Meletakkan komputer } \\
\text { dan CPU }\end{array}$ & $\begin{array}{l}\text { Area datar untuk meletakkan } \\
\text { komputer dan CPU }\end{array}$ & $\begin{array}{l}\text { Area datar untuk meletakkan } \\
\text { keyboard dan mouse }\end{array}$ \\
\hline 5. & $\begin{array}{l}\text { Meletakkan / } \\
\text { Mengambil uang }\end{array}$ & $\begin{array}{l}\text { Space/penyimpanan khusus } \\
\text { untuk meletakkan dan } \\
\text { mengambil uang }\end{array}$ & $\begin{array}{l}\text { Memiliki ruang dan laci } \\
\text { khusus untuk } \\
\text { meletakkan peralatan } \\
\text { tulis kerja dan uang }\end{array}$ \\
\hline 6. & $\begin{array}{l}\text { Meletakkan alat tulis } \\
\text { kerja (pulpen, penggaris, } \\
\text { gunting dan lain-lain) }\end{array}$ & $\begin{array}{l}\text { Penyimpanan untuk } \\
\text { meletakkan alat tulis kerja }\end{array}$ & \\
\hline
\end{tabular}

Berikut ini adalah titik-titik keergonomisan pada produk:

1. Antropometri yang digunakan untuk menentukan tinggi meja adalah dimensi antropometri tebal paha dan tinggi lipat lutut. Jenis antropometri yang digunakan untuk kelompok pria 50\% persentil, yaitu tebal paha $140 \mathrm{~mm}$ ditambah tinggi lipat lutut $445 \mathrm{~mm}$ sama dengan $585 \mathrm{~mm}$. Perlu adanya penambahan $30 \mathrm{~mm}$ untuk toleransi sepatu, $100 \mathrm{~mm}$ untuk kelonggaran paha pada saat duduk. Oleh karena tinggi paha manusia akan relatif bertambah pada saat duduk menggunakan sepatu yang disebut pengaruh dinamis (dynamic effect). Sehingga total tinggi meja keseluruhan $=715 \mathrm{~mm}$. Ini adalah tinggi meja yang sesuai dengan perancangan riil. Standar yang digunakan untuk tinggi meja depan adalah $750 \mathrm{~mm}$. Berdasarkan data jenis dan fasilitas meja kerja dijelaskan bahwa tinggi meja kerja pada umumnya berkisar $75 \mathrm{~cm}$ dan dari data antropometri menurut Panero dan Zelnik disebutkan bahwa tinggi meja $(\mathrm{N})$ berkisar antara 73,7 - 76,2 cm. Jadi, tinggi produk meja kerja yang dirancang boleh kurang dari $70 \mathrm{~cm}$ dan tidak lebih dari 76,2 cm.

2. Antropometri yang digunakan untuk menentukan ukuran handle meja adalah lebar telapak tangan. Jenis antropometri yang digunakan untuk kelompok wanita 50\% persentil, yaitu $81 \mathrm{~mm}$. Berdasarkan data dimensi manusia dan ruang interior menurut Panero dan Zelnik disebutkan bahwa dimensi tangan (K) berkisar 8,2 
Etwin Fibrianie, Randu Chan Limin, Desain Meja Administrasi Swajasa 57

cm. Jadi, dimensi lebar telapak tangan yang dirancang tidak boleh kurang dari $73 \mathrm{~cm}$ agar ruang gerak tangan tidak sempit.

3. Antropometri yang digunakan untuk menentukan panjang meja adalah jarak bentang dari ujung jari tangan kiri ke kanan. Jenis antropometri yang digunakan untuk kelompok pria adalah 50\% persentil, yaitu $1.663 \mathrm{~mm}$. Maka ditentukan panjang meja depan $1.600 \mathrm{~mm}$ dan 900 mm untuk panjang meja bagian samping dikarenakan menyesuaikan ukuran luas ruangan admin dan permintaan pengguna. Berdasarkan data jenis dan fasilitas meja kerja dijelaskan bahwa tinggi meja kerja pada umumnya berkisar $180 \mathrm{~cm}$ dan dari data antropometri ruang menurut Panero dan Zelnik disebutkan bahwa panjang meja bagian depan (E) berkisar antara 152,4 - 182,9 cm dan panjang meja bagian samping (C) berkisar antara 76,2 -121,9 cm. Jadi, panjang produk meja kerja bagian depan yang dirancang tidak kurang dari $150 \mathrm{~cm}$ dan tidak lebih dari 182,9 cm dan panjang meja bagian samping boleh kurang dari $90 \mathrm{~cm}$ dan tidak lebih dari $121,9 \mathrm{~cm}$.

4. Antropometri yang digunakan untuk menentukan lebar ruang kaki pada kolong meja kerja adalah lebar panggul. Jenis antropometri yang digunakan untuk kelompok pria 95\% persentil, yaitu 371 mm. Maka ditentukan lebar ruang kaki meja kerja 400 mm. Berdasarkan data antropometri posisi duduk menurut
Panero dan Zelnik disebutkan bahwa rentang/lebar panggul (G) berkisar 43,4 cm. Jadi, lebar panggul untuk menentukan lebar ruang kaki pada kolong meja tidak kurang dari $40 \mathrm{~cm}$ dan tidak lebih dari 43,4 cm.

5. Antropometri yang digunakan untuk menentukan kedalaman ruang kaki pada meja kerja adalah jarak dari pantat ke lutut. Jenis antropometri yang digunakan untuk kelompok pria 50\% persentil, yaitu $545 \mathrm{~mm}$. Berdasarkan data antropometri ruang menurut Panero dan Zelnik disebutkan bahwa jarak pantat-lutut berkisar 57,1 cm. Jadi, jarak pantat-lutut untuk menentukan kedalaman ruang kaki pada kolong meja tidak kurang dari 53,7 cm dan tidak lebih dari 57,1 cm.

6. Antropometri yang digunakan untuk menentukan lebar meja adalah jarak genggaman tangan ke punggung pada posisi tangan ke depan. Jenis antropometri yang digunakan untuk kelompok pria 50\% persentil, yaitu 708 mm. Maka ditentukan lebar meja depan $650 \mathrm{~mm}$ dikarenakan menyesuaikan lebar ruangan penempatan meja. Berdasarkan data antropometri ruang menurut Panero dan Zelnik disebutkan bahwa lebar meja bagian depan (H) berkisar antara 76,291,4 cm dan lebar meja bagian samping (J) berkisar antara 45,7 - 55,9 cm. Jadi, lebar meja bagian depan tidak kurang dari $60 \mathrm{~cm}$ dan lebar meja bagian samping tidak kurang dari $40 \mathrm{~cm}$. 


\section{Analisis konfigurasi dilakukan guna}

mendapatkan susunan dari tiap-tiap komponen yang terdapat pada Meja Admin Swajasa57. Adapun komponen yang terdapat pada produk adalah: (1) Rak peletakkan 3 macam printer yang berbeda, (2) Laci untuk menyimpan alat tulis kantor dan laci untuk uang, (3) Space datar khusus untuk menulis, meletakkan komputer dan CPU. Ukuran ruang kerja admin swajasa57 ini adalah $4 \mathrm{~m}$ x 2,5m. Yang dimana admin swajasa57 ini hanya mempunyai seorang admin pada ruangan tersebut. Ruangan memiliki akses keluar masuk 2 pintu dari depan dan belakang dan terdapat pintu bagian tengah ruang. Memiliki 2 meja yang dikhususkan untuk pelanggan dan kursi pelanggan. Komposisi konfigurasi meja ditunjukkan dalam gambar 1 dan 2.

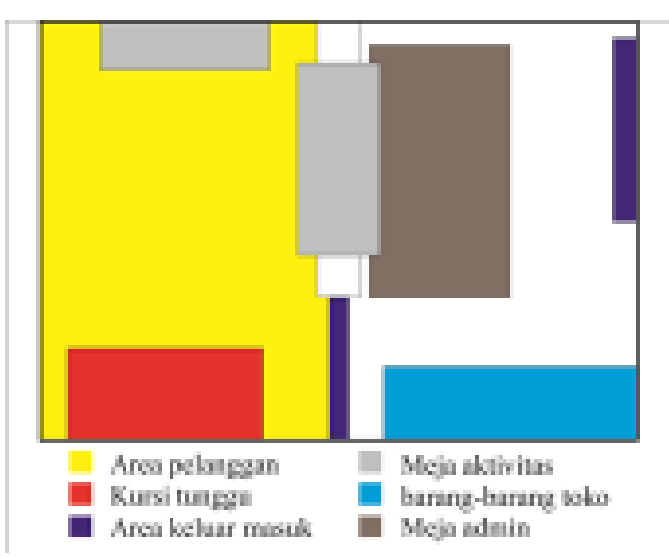

Gambar 1. Konfigurasi produk

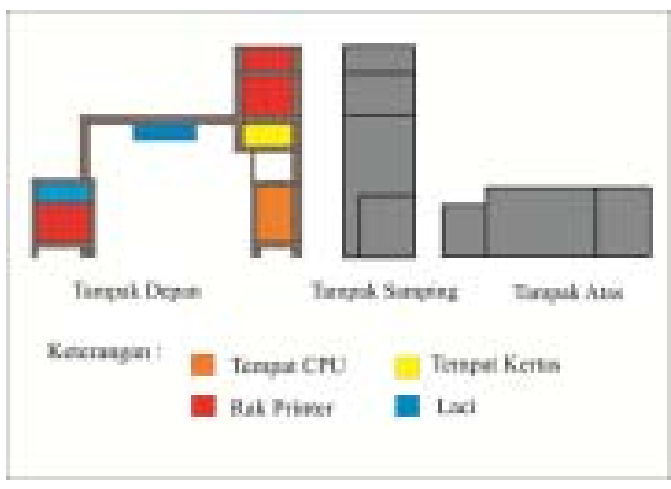

Gambar 2. Konfigurasi produk

Pada analisis konfigurasi di atas terdapat space printer stempel dan laci alat tulis di sebelah kiri bawah. Penempatan laci kasir tepat di tengah meja, sedangkan rak printer lainnya, tempat kertas printer bill, CPU di sebelah kanan. Karena kebanyakan orang Indonesia lebih sering menggunakan atau mengambil benda dengan tangan kanan sehingga peletakkan pada konfigurasi di atas lebih efisien penggunaannya serta kesesuain denah ruangan yang tepat dengan Swajasa57.

Analisis sistem dilakukan guna menentukan sistem apa yang akan dipakai pada produk meja admin Swajasa57 sehingga akan memudahkan dalam aktivitas pengguna ketika akan menggunakan produk ini. Sistem yang digunakan yaitu:

1. Sistem Sambungan Sekrup dan Paku. Meja ini menggunakan sambungan sekrup dan paku dikarenakan bagian meja yang memiliki bentuk kompleks dan tidak berubah-ubah atau permanen. Sedangkan sekrup digunakan untuk menyambung apabila ada bagian meja yang semi permanen seperti bagian stainless dan laci. 
Etwin Fibrianie, Randu Chan Limin, Desain Meja Administrasi Swajasa 57

2. Sistem Geser. Sistem geser menggunakan rel mekanik yaitu rel yang dibuat khusus dari kombinasi bahan logam, plastik atau karet dan didesain sedemikian rupa untuk meningkatkan utilitas kotak laci. Posisi pemasangan rel laci juga bervariasi pada bagian bawah laci, bagian samping atau bagian atas, yang berarti menggantung kotak laci. Mengatasi kelemahan rel kayu agar kotak laci tidak terjatuh pada saat dibuka juga menjadi salah satu alasan mengunakan rel laci mekanis. Bahkan sudah terdapat rel laci mekanis yang memungkinkan kotak laci bisa 'dikeluarkan' secara keseluruhan. Artinya laci bisa dibuka semaksimal mungkin hingga seluruh bagian dalam laci bisa dilihat.

3. Sistem Kuncian. Furniture key yang digunakan adalah jenis kuncian drawer lock, agar pintu terkunci dengan baik, karena kuncian jenis ini merupakan kuncian yang paling umum digunakan untuk sebuah laci. Kuncian juga mudah digunakan saat laci sering digunakan saat mengambil uang dan berdampak kepada keamanan yang lebih safety untuk laci kasir.

Analisis material dilakukan guna menentukan material yang baik yang akan digunakan pada produk meja admin Swajasa57 ini. Sehingga nantinya akan menghasilkan produk yang aman dengan kegiatan pengguna. Dari analisis material yang telah dilakukan, nilai paling besar dihasilkan oleh material kayu jenis plywood, sehingga material inilah yang akan menjadi salah satu material utama untuk membuat meja admin Swajasa57.

Analisis bentuk dilakukan guna menentukan gaya desain apa yang sesuai dengan konsep yang diambil dan akan diaplikasikan pada produk Meja Admin Swajasa 57. Dengan konsep desain compact, yaitu rapi, bersatu-padu dan sesuai dengan fungsinya. Dapat dilihat pada bagian meja yang memliki 3 space khusus untuk 3 jenis printer berbeda, penempatan komputer, central processor unit (CPU) dan laci kasir.

Melihat dari analisis segmentasi dan konsep yang dipilih berdasarkan keinginan pengguna, maka gaya desain yang digunakan adalah modern. Dalam gaya desain modern bentuk ini lebih mengarah ke gaya desain Modern Bauhaus dikarenakan banyak bentuk yang akan menggunakan bentukbentuk geometris atau bentuk persegi dan setiap ujung bagian meja Nampak runcing tanpa lengkungan serta bentuk sederhana yang sering dijumpai pada gaya desain bauhaus. Karena gaya modern bauhaus adalah gaya desain yang simple, bersih, fungsional, stylish, tanpa ornamen dan bahan menggabungkan dengan bahan chrome metal/stainless dan baja. Gaya desain ini dapat dijumpai dalam bagian penempatan printer bagian atas.

Proses desain langkah awalnya adalah dengan mendesain bentuknya. Pertama-tama mendesain bentuk awal terdiri dari beberapa alternatif desain. Alternatifalternatif desain ini selnjutnya dianalisis karakternya, kemudian dipilih alternatif mana 
Vol. 2, No. 2, April 2015

yang memenuhi spesifikasi desain yang telah ditentukan. Dari beberapa alternatif desain, setelah melalui penilaian terpilih alternatif desain yang ditunjukkan dalam gambar 3 .

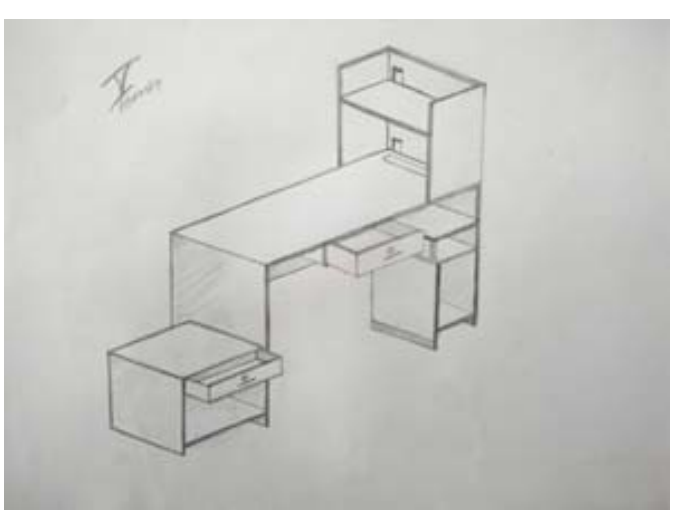

Gambar 3. Alternatif Desain terpilih

Alternatif desain terpilih ini selanjutnya dikembangkan lagi, menjadi beberapa alternatif. Selanjutnya dilakukan analisis karakternya, sampai terpilih agar lebih maksimal mendekati produk real sehingga menjadi desain final. Desain yang teripilih dari pengembangan alternatif tahap sebelumnya ditunjukkan dalam gambar 4.

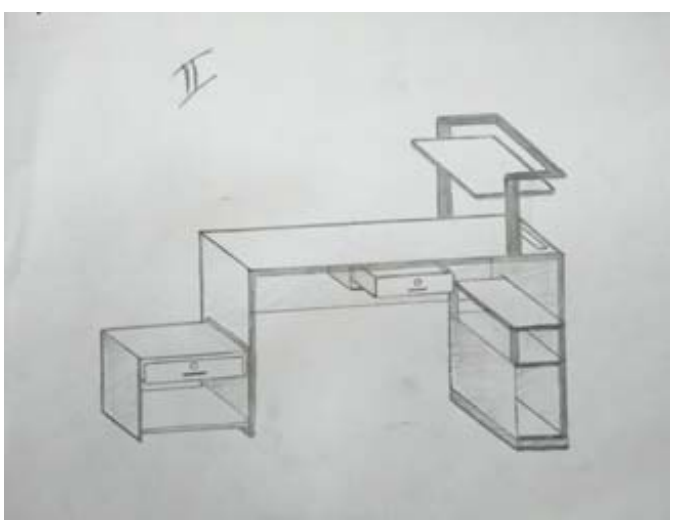

Gambar 4. Desain final.
Desain final yang teripilih

selanjutnya dijabarkan sesuai kaidah industri yang baku agar bisa diproduksi. Yaitu dalam bentuk gambar presentasi, gambar isometri, gambar modelling, gambar tampak, gambar potongan, gambar detail, gambar urai dan animasi produk. Setelah itu proses desain dilanjutkan dengan pembuatan prototype produk sesungguhnya yang siap dioperasikan.

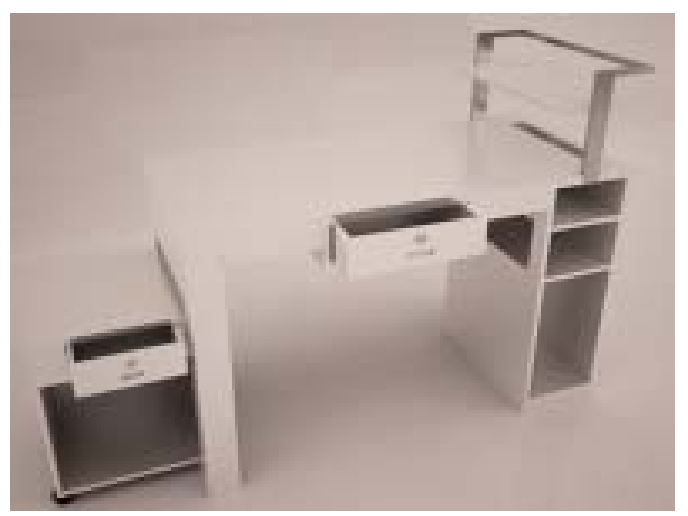

Gambar 5. Gambar presentasi

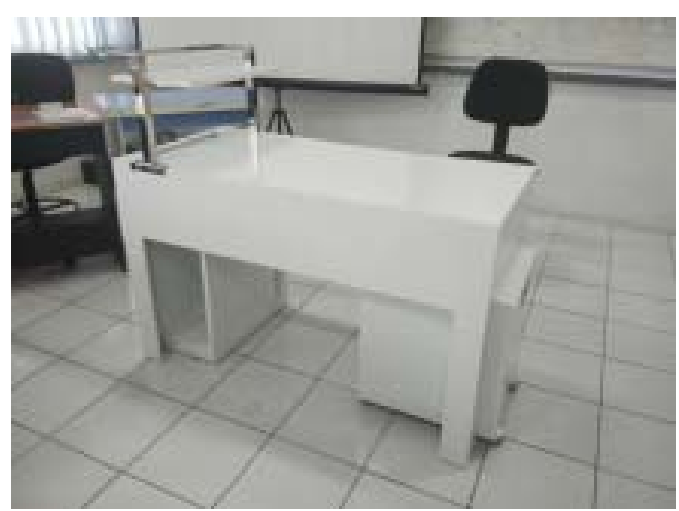

Gambar 6. Gambar prototipe 


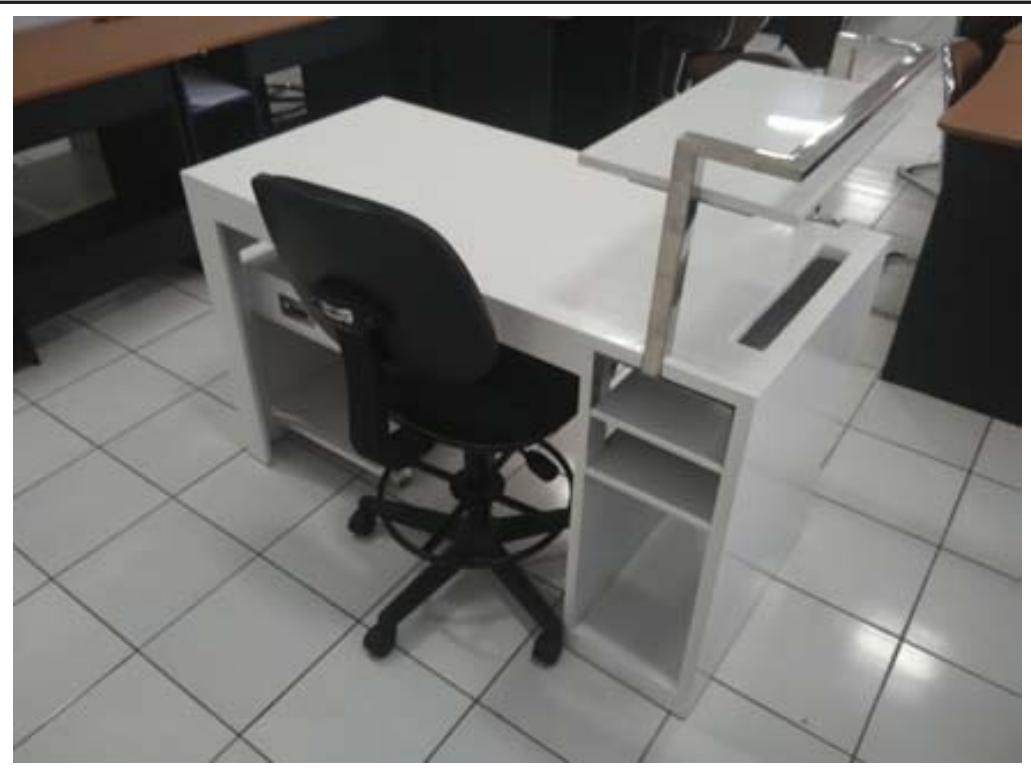

Gambar 7. Gambar prototipe

\section{Kesimpulan}

Adapun hasil dari perancangan dan pembuatan "Desain Meja Admin Swajasa57", dapat ditarik kesimpulan: Meja kerja yang dikhususkan untuk Admin Swajasa57 ini dirancang sesuai keinginan pengguna baik dari segi fungsi dan estetis. Dan telah berinovasi menjadi produk yang fungsional dari meja kerja yang sebelumnya dengan fasilitas seperti rak untuk peletakkan printer, kertas/map, laci kasir, alat-alat tulis, komputer serta penempatan Central Processing Unit yang diperlukan. Dan estetika produk dapat dilihat dari segi warna dan perpaduan bahan stainless pada produk. Suasana dan tempat kerja haruslah nyaman. Karena ruang kantor yang sempit, maka ukuran dan bentuk dibuat menyesuaikan ruang dan fasilitas kebutuhan yang diperlukan pengguna.

Saran yang dapat diberikan adalah untuk di masa mendatang jika produk ini akan 58 diproduksi secara massal, perlu diadakan redesign untuk inovasi bentuk dengan tambahan fungsi privasi pada meja kerja, serta warna yang lebih beragam sesuai keinginan pasar dan ukuran yang disesuaikan dengan ruangan standar kantor publik lainnya. 
DAFTAR PUSTAKA

Alfiago, S. (2012). Elemen Mesin (Sambungan Mur Baut). 06 Agustus, 2015. http:// ren3energi.com/2012/09/elemen-mesin-sambungan-mur-baut.html

Bhavati, A. (2014). Jenis-Jenis Perlengkapan Kantor. 13 Februari, 2015. http:// anugerahdino.com/2014/02/jenis-jenis-perlengkapan-kantor.html

Hindarto, M.P. (2006). Warna Untuk Desain Interior. Yogyakarta: Penerbit Media Pressindo.

Inu, O. (2013). Fungsi Meja Kantor Dan Cara Memilihnya. 09 Februari, 2015. http:// rajabrankas.com/2013/02/fungsi-meja-kantor-dan-cara-memilihnya.html

Kamus besar bahasa Indonesia online, Badan Pengembangan dan Pembinaan Bahasa, Kemdikbud. 3 maret, 2016. https://kbbi.web.id

Kurniawan, D.P. (2013). Plus Minus Furniture Lapis HPL. 12 Maret, 2015. http:// dhianfurniture.com/2013/12/plus-minus-furniture-lapis-hpl.html

Lawson, B. (1990). How Designer Think (2rd ed). The University Press.

Marizar, E.S. (2005). Designing Furniture. Yogyakarta: Penerbit Media Pressindo.

Media Informasi Teknik Industri. (2011). Materi kuliah Elemen mesin - Sambungan Sekrup. 01 April, 2015. http://fteknikindustri. com/2011/11/materi-kuliah-fisika-dasarsambungan.html

Ningsih M. 2015. Desain Meja Kerja Ketua Program Studi Desain Produk Jurusan Desain Politeknik Samarinda. Laporan Tugas Akhir pada Jurusan Desain Produk Politeknik Samarinda.

Oscar. (2011). Jenis-Jenis Kayu Olahan. 24 Februari, 2015. http:// oscarfurniturestore.com/2011/12/jenis-jenis-kayu-olahan/

Palgunadi, B. (2008). Desain Produk 3: Mengenal Aspek Disain. Bandung: Penerbit ITB.

Panero, J., \& Zelnik, M. (2003). Dimensi Manusia \& Ruang Interior: Buku Panduan Untuk Standar Pedoman Perancangan. Jakarta: Penerbit Erlangga. 